\title{
INPATIENT NURSES' PERCEPTION ON THE IMPLEMENTATION OF ACUTE CARE NURSING IN THE HASANUDDIN UNIVERSITY HOSPITAL
}

\author{
Rahmat Hidayat ${ }^{1}$, Rini Rachmawaty ${ }^{2}$, Ilkafah $^{3}$ \\ ${ }^{1}$ Rumah Sakit Universitas Hasanuddin, Makassar \\ ${ }^{2,3}$ Dosen, Program Studi Ilmu Keperawatan Universitas Hasanuddin, Makassar
}

email : rini.rachmawaty@unhas.ac.id.ilkafah@unhas.ac.id

\begin{abstract}
Introduction: Acute care is a type of time-sensitive care, this is due to an acute condition requiring rapid intervention. Acute conditions that exist in the inpatient unit would require special care in handling. This acute condition can affect many things, one of which is the patient satisfaction. With proper treatment for acute cases, the course will improve patient satisfaction itself. However, to date, acute care has been poorly defined and inadequately supported in most developing health systems. Aims of Study: This research aims to determine nurses' perception on the implementation of inpatient acute nursing care in the Hasanuddin University Hospital. Method: This research was a qualitative method, data collection using individual interviews against ten participants (inpatient nurses) and validity checks of the data that utilizes something beyond the data. Data analyze used thematic analysis. Result: The results of the research yield four themes. Those four themes are perception of acute conditions, supporting factors in the management of patients with acute conditions, inhibiting factors in the management of patients with acute conditions, and nurses' hope for acute care. Conclusion: From this research it is known that the incidence of acute conditions in the inpatient unit of Hasanuddin University Hospital less than chronic conditions. To handle acute cases, nurse in the inpatient unit take action early by monitoring vital signs, then immediately gave emergency action if necessary, while collaborating with the doctor. Supporting factors for nurses is the availability of emergency trolly, as well as cooperation among nurses who are good. Whereas the inhibiting factor is the number of nurses who are still lacking and the absence of code blue team. It is expected that the health institution establishes a rapid response team (code blue), whose role will quickly and efficiently handle serious or acute patient.
\end{abstract}

Keywords: Perception of nurses, acute care, inpatient unit

\section{PENDAHULUAN}

Kesehatan merupakan hal yang sangat penting bagi semua orang. Organisasi kesehatan dunia World Health Organization (WHO) mendefinisikan kesehatan sebagai suatu keadaan fisik, mental dan kesejahteraan sosial yang lengkap dan bukan hanya bebas dari penyakit atau kelemahan (WHO, 1946). Kesehatan yang baik tentunya ditunjang oleh fasilitas kesehatan yang baik pula. Ada banyak fasilitas kesehatan yang dapat berperan dalam meningkatkan derajat kesehatan di Indonesia, salah satunya yaitu rumah sakit.
Dalam menjalankan fungsinya, sebuah rumah sakit harus memiliki sistem yang baik di semua aspek, termasuk dari segi pelayanan terhadap pasiennya. Pelayanan terhadap pasien di sebuah rumah sakit ini melibatkan seluruh tenaga kesehatan yang ada, termasuk tenaga perawat.

Pelayanan keperawatan merupakan bagian integral dari pelayanan kesehatan di rumah sakit yang mempunyai posisi yang sangat strategis dalam upaya meningkatkan mutu pelayanan dan pemuasan konsumen yang datang ke rumah sakit. Jumlah tenaga keperawatan 
mendominasi tenaga kesehatan secara menyeluruh, juga sebagai penjalin kontak pertama dan terlama denugan pelanggan (pasien dan keluarganya) (Mayasari, 2009).

Pelayanan keperawatan tentunya berbeda untuk tiap jenis penyakit. Di ruang rawat inap sendiri terdapat berbagai macam jenis penyakit. Pasien dengan kondisi akut akan berbeda pelayanannya dengan yang kronis. Kasus-kasus penyakit akut sendiri sudah sering ditemukan di rumah sakit, khususnya di ruang rawat inap.

Sebuah penelitian retrospektif yang dilakukan oleh Yusuf (2011), ditemukan bahwa untuk mengetahui jumlah kasus diare pada anak di ruang rawat inap RSUD dr. Zainoel Abidin Banda Aceh melalui rekam medik yang didata sejak 1 Juli 2009 s/d 30 Juni 2010. Hasil dari penelitian tersebut menunjukkan bahwa ada sebanyak 104 kasus diare pada anak di ruang rawat inap, dimana $84(80 \%)$ di antaranya merupakan diare akut.

Pelayanan untuk penyakit akut merupakan tipe pelayanan yang sensitif dalam hal waktu, hal ini dikarenakan penyakit akut membutuhkan intervensi/tindakan yang cepat (rapid intervention). Namun sampai saat ini, perawatan akut masih belum jelas dan tidak begitu didukung dalam sebagian besar sistem kesehatan berkembang (WHO, 2013). Padahal jenis penyakit (akut, kronis dan sebagainya) juga dapat mempengaruhi banyak hal, salah satunya yaitu tingkat kepuasan pasien yang ada di ruang rawat inap.

Penelitian yang telah dilakukan oleh Anjaryani (2009) di ruang rawat inap RSUD Tugurejo dengan jumlah sampel sebanyak 60 pasien menunjukkan bahwa ada pengaruh dari jenis penyakit dengan tingkat kepuasan pasien. Hal tersebut juga disampaikan oleh pasien pada saat wawancara mendalam yang dilakukan oleh peneliti, bahwa perawat seharusnya juga memperhatikan masing-masing penyakit pasien supaya memahami kondisi pasien, jika banyak pertanyaan dari pasien berkaitan dengan penyakit yang dideritanya.

Salah satu rumah sakit yang ada di Indonesia adalah Rumah Sakit Pendidikan Unhas, yang bertempat di kota Makassar. Rumah sakit ini mulai beroperasi pada tahun 2010 dan merupakan sebuah rumah sakit bertipe B. Di rumah sakit ini ruang rawat inap dibagi ke dalam 5 kelas, yaitu kelas VVIP (10 perawat), kelas VIP (18 perawat), kelas I (22 perawat), kelas II dan III (29 perawat), serta ruang rawat inap mata (9 perawat). Berdasarkan hasil wawancara dengan kepala bagian keperawatan RSP Unhas, model pelayanan keperawatan yang sedang diterapkan di ruang rawat inap saat ini ialah MPKP dengan modifikasi pendekatan keperawatan primer.

Sesuai yang dijelaskan sebelumnya, bahwa kasus akut yang ada di ruang rawat inap harus ditangani dengan cepat dan tepat. WHO (2013) menyebutkan bahwa perawatan akut sampai sekarang masih belum jelas dan tidak begitu didukung dalam sebagian besar sistem kesehatan berkembang. Untuk itu peneliti merasa perlu mengetahui persepsi perawat di ruang rawat inap tentang pelaksanaan pelayanan keperawatan akut di RSP Unhas.

\section{METODE}

Jenis penelitian ini adalah penelitian kualitatif secara umum, tanpa adanya pendekatan tertentu. Penelitian ini dilakukan di ruang rawat inap kelas 1, 2 dan 3 RSP Unhas, dimana populasi dalam penelitian ini mencakup seluruh perawat yang bekerja di ruang rawat inap kelas 1, 2 dan 3 RSP Unhas. Sampel dalam penelitian ini dipilih dengan menggunakan teknik purposive sampling.

Pengambilan data dilakukan dengan wawancara individu terhadap 10 partisipan. Konsep triangulasi tetap dilakukan dengan menggunakan teknik field note serta triangulasi data dengan validasi data kepada perawat selain 
partisipan. Adapun teknik analisa data yang digunakan adalah analisa data tematik pada pendekatan kualitatif menurut Creswell.

\section{HASIL}

Partisipan dalam penelitian ini ialah perawat yang bekerja di ruang rawat inap kelas 1 (Sandeq) serta kelas 2 dan 3 (Katinting) RSP Unhas dengan pendidikan terakhir minimal DIII Keperawatan dan S1 Ners serta telah bekerja minimal 1 tahun. Karakteristik partisipan lebih lanjut tercantum dalam Tabel 1.

Wawancara yang dilakukan terhadap sepuluh partisipan tersebut menghasilkan empat buah tema yang menggambarkan persepsi dari perawat tentang keperawatan akut di ruang rawat inap RSP Unhas. Tematema tersebut ialah persepsi tentang kondisi akut, faktor pendukung dalam penatalaksanaan pasien dengan kondisi akut, faktor penghambat dalam penatalaksanaan pasien dengan kondisi akut, serta harapan perawat untuk keperawatan akut.

Tema pertama tentang kondisi akut di ruang rawat inap menghasilkan dua kategori. Kategori pertama ialah identifikasi kondisi akut di rawat inap, dimana hasil wawancara menunjukkan bahwa di ruang rawat inap jarang

terjadi kondisi akut, dan justru lebih sering terjadi kondisi kronis. Kategori kedua ialah penanganan untuk kondisi akut.

Tema kedua tentang faktor pendukung dalam penatalaksanaan pasien dengan kondisi akut menghasilkan dua kategori. Kategori pertama yaitu tersedianya trolly emergency dan kategori kedua yaitu kerja sama yang baik antar perawat.

Tema ketiga tentang faktor penghambat dalam penatalaksanaan pasien dengan kondisi akut menghasilkan tiga kategori. Kategori pertama ialah kurangnya jumlah tenaga perawat, kategori kedua ialah tidak adanya tim code blue dan kategori ketiga yaitu tidak adanya SOP tentang keperawatan akut.

Sedangkan tema terakhir tentang harapan perawat untuk keperawatan akut menghasilkan empat kategori. Kategori pertama ialah peningkatan kualitas perawat, kategori kedua ialalh penambahan jumlah tenaga perawat, kategori ketiga ialah pengadaan tim code blue dan kategori keempat ialah pengadaan SOP keperawatan akut.

\section{PEMBAHASAN}

\section{Persepsi tentang Kondisi Akut}

Tema pertama mengenai persepsi tentang kondisi akut di ruang rawat inap menghasilkan dua kategori. Kedua kategori tersebut ialah identifikasi kondisi akut di rawat inap serta penanganan untuk kondisi akut.

Beberapa partisipan mengungkap-kan bahwa di ruang rawat inap lebih sering terjadi kondisi kronis daripada kondisi akut. Kondisi akut sendiri dalam dunia kesehatan berarti kondisi yang datang secara tiba-tiba, berlangsung secara singkat dan berat (Anderson, 2011).

Beberapa partisipan menggambar-kan perbandingan antara kondisi akut dan kronis dalam bentuk persen, dimana jumlah kasus akut di ruang rawat inap hanya sekitar 20-40 persen saja jika dibandingkan dengan kasus kronis. Hal tersebut terlihat dari pernyataan beberapa responden sebagai berikut:

"kalau kondisi akut ada ji tapi lebih banyak yang kronis dek... persentasinya kalau $100 \% .$. mungkin 30\% ji, 70 yang kronisnya" (P5)

"Mmm biasa, ya, nda terlalu banyak sih sebenarnya kalau di sini kasus akut..." (P7) 


\begin{tabular}{|c|c|c|}
\hline Karakteristik Partisipan & $\mathbf{N}$ & $\%$ \\
\hline \multicolumn{3}{|l|}{ 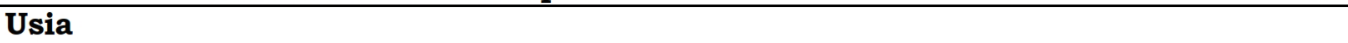 } \\
\hline 25 tahun & 3 & 30 \\
\hline 26 tahun & 2 & 20 \\
\hline 27 tahun & 4 & 40 \\
\hline 28 tahun & 0 & 0 \\
\hline 29 tahun & 0 & 0 \\
\hline 30 tahun & 1 & 10 \\
\hline Total & 10 & 100 \\
\hline \multicolumn{3}{|l|}{ Jenis Kelamin } \\
\hline Laki-Laki & 2 & 20 \\
\hline Perempuan & 8 & 80 \\
\hline Total & 10 & 100 \\
\hline \multicolumn{3}{|l|}{ Pendidikan Terakhir } \\
\hline DIII Kep & 2 & 20 \\
\hline S1 Ners & 8 & 80 \\
\hline Total & 10 & 100 \\
\hline \multicolumn{3}{|l|}{ Lama Kerja } \\
\hline$<3$ tahun ( 1 tahun 3 bulan -2 tahun) & 3 & 30 \\
\hline$\geq 3$ tahun ( 3 tahun 3 bulan -6 tahun) & 7 & 70 \\
\hline Total & 10 & 100 \\
\hline \multicolumn{3}{|l|}{ Status Kepegawaian } \\
\hline Kontrak & 9 & 90 \\
\hline PNS & 1 & 10 \\
\hline Total & 10 & 100 \\
\hline \multicolumn{3}{|l|}{ Jabatan } \\
\hline Perawat pelaksana & 8 & 80 \\
\hline Perawat primer & 1 & 80 \\
\hline Kepala ruangan & 1 & 10 \\
\hline Total & 10 & 100 \\
\hline \multicolumn{3}{|l|}{ Ruangan } \\
\hline Sandeq & 3 & 30 \\
\hline Katinting & 7 & 70 \\
\hline Total & 10 & 100 \\
\hline
\end{tabular}

Tabel 1. Karakteristik partisipan.

Kondisi ini juga terjadi pada penelitian yang dilakukan oleh Bauk et al (2013) yang meneliti tentang hubungan Karakteristik Pasien Dengan Kualitas Pelayanan: Persepsi Pasien Pelayanan Rawat Inap RSUD Majene Tahun 2013. Penelitian ini melibatkan semua pasien yang ada di ruang rawat inap RSUD Majene, dimana karakteristik dari pasien berdasarkan jenis penyakitnya ialah lebih banyak pasien dengan kondisi kronis $(53,2$ persen) dibandingkan dengan kondisi akut (46,8 persen).

Kondisi akut tersebut tentunya harus diberi penanganan yang baik oleh perawat. Beberapa partisipan menyebutkan bahwa saat ada pasien dengan kondisi akut, mereka terlebih dahulu akan mengecek tanda vital pasien. Jika pasien membutuhkan tindakan emergency, misalnya pembebasan jalan napas dan RJP, maka perawat akan segera melakukan tindakan tersebut. Perawat juga tetap berkolaborasi dengan dokter. Jika dokter tidak ada di ruangan maka instruksi dari dokter disampaikan ke perawat melalui telpon, dengan tetap memperhatikan "tebak sebar". Hal ini diunngkapkan oleh partisipan dengan pernyataan sebagai berikut:

"Biasanya langsung kita TTV, lalu konfirmasi ke dokter. Kalau airwaynya biasanya kita yang langsung bebaskan jalan napasnya toh. Kalau ridak ada dokter, kita pakai sistem tebak sebar" (P4)

"kita observasi dulu kondisinya, TTV nya. Misalkan tibatiba henti jantung ya kita langsung RJP. Untuk dokter kita telepon, dan 
untuk instruksinya kita pakai tebak sebar" $(P 7)$

Tebak sebar ini merupakan sebuah istilah yang biasa digunakan di RSP Unhas. Tebak sebar berasal dari singkatan TBaK SBAR. TBaK sendiri merupakan singkatan dari tulis kembali, baca kembali dan konfirmasi kembali. Partisipan menjelaskan implementasi TBaK, yaitu saat mendengar instruksi dari dokter via telpon, perawat harus betul-betul melakukan konfirmasi kembali terhadap semua instruksi yang disampaikan. Sebaiknya saat melakukan konfirmasi ada orang lain atau perawat lain yang juga mendengarkan dan menjadi saksi. Barenfanger (dalam Nazri, Juhariah, \& Arif, 2015) mengungkapkan bahwa perawat yang membaca kembali informasi ketika menelepon dokter dapat menurunkan resiko medical error dan meningkatkan keselamatan pasien.

Kemudian SBAR juga merupakan sebuah singkatan yang berarti Situation, Background, Assessment, and Recommendation. Partisipan menjelaskan bahwa saat menelpon dokter, perawat menjelaskan semua kondisi pasien, dimana perawat menjelaskan tentang keadaan pasien (situation), riwayat penyakit pasien (background), tindakan yang sudah dan sedang dilakukan (assessment), lalu meminta saran atau rekomendasi dari dokter (recommendation) dengan memperhatikan TBaK tadi. Renz (dalam Nazri, Juhariah, \& Arif, 2015) menjelaskan bahwa model teknik komunikasi SBAR dapat membantu perawat untuk mengorganisasi cara berpikir, mengorganisasi informasi, dan merasa lebih percaya diri berkomunikasi dengan dokter.

\section{Faktor pendukung dalam penata- laksanaan pasien dengan kondisi akut}

Tema kedua tentang faktor pendukung dalam penatalaksanaan pasien dengan kondisi akut menghasilkan dua kategori. Kategori pertama yaitu tersedianya trolly emergency dan kategori kedua yaitu kerja sama yang baik antar perawat.

Partisipan menyebutkan bahwa di ruang rawat inap sudah tersedia trolly emergency. Trolly emergency merupa-kan troli yang berisi peralatan dan perlengkapan untuk melakukan resu-sitasi kardiopulmoner dan untuk menangani kegawatdaruratan lainnya. Troli emergensi ini digunakan di dalam area instalasi rawat inap, dan hanya boleh digunakan bila terjadi kondisi gawat darurat (Rachmanta, 2015).

Menurut partisipan, trolly emergency yang tersedia sudah sangat lengkap, termasuk obat-obatan yang ada di dalamnya. Beberapa obat emergency seperti epinefrin, dobutamin, dopamin, dan lain-lain juga tersedia di trolly tersebut. Setiap selesai digunakan, trolly akan segera diisi kembali, dimana obat-obat yang sudah terpakai akan segera diganti, sehingga dapat digunakan kembali saat muncul kasus emergency. Hal tersebut diungkapkan oleh partisipan sebagai berikut.

"kalau trolly emergency di sini dek ada ji, dan lengkap isinya. Terus selalu di update, jadi misalkan ada obat di trolly yang sudah dipakai, langsung diisi kembali,..." (P4)

"trolly emergency ada ji di sini, terus menurutku lengkap ji isinya. Obat-obat yang ada itu kaya' epinefrin, sa atrofi, faskon, dobutamin, dopamin, dan lain-lain." (P8)

Faktor pendukung yang lain ialah kerja sama antar perawat yang terjalin dengan baik. Para partisipan menutur-kan bahwa saat tim mereka mengalami kewalahan dalam melayani pasien, maka tim lain yang tidak sibuk akan turut membantu, begitu pula sebaliknya. Kerja sama antar perawat yang baik ini menurut para partisipan sangat membantu dalam melaksanakan pekerjaan mereka sebagai perawat. Hal tersebut diungkapkan oleh partisi- 
pan sebagai berikut.

“...kalau di sini selalu kita kolaborasi juga sih dengan tim-tim yang lain, jadi dalam melaksanakan ee apa lagi namanya itu, kita selalu kolaborasi, jadi kita tidak pernah ji kesulitan kalau misalkan ada pasien-pasien begitu..." (P6)

“...Karena yang di sini kan sistem tim juga toh, jadi kalau ada satu tim yang bermasalah ya tim yang lain juga turut membantu ji, kaya'begitu..." (P7)

Perawat merupakan pekerjaan sangat memerlukan keahlian dan keterampilan khusus untuk dapat memenuhi kebutuhan pasien yang mencakup kebutuhan biologis, psikologis, sosiologis dan spiritual pasien. Hal ini dapat diwujudkan dengan menolong, menghibur, berbagi dan bekerja sama dengan perawat lain, sehingga terwujudnya pelayanan yang komprehensif (Rudyanto, 2013).

\section{Faktor penghambat dalam penata- laksanaan pasien dengan kondisi akut}

Tema ketiga tentang faktor penghambat dalam penatalaksanaan pasien dengan kondisi akut menghasilkan tiga kategori. Kategori pertama ialah ku-rangnya jumlah tenaga perawat, kategori kedua ialah tidak adanya tim code blue dan kategori ketiga ialah tidak adanya SOP tentang keperawatan akut.

Semua partisipan yang terlibat dalam penelitian ini menyampaikan bahwa jumlah tenaga perawat yang ada di ruang rawat inap baik itu kelas 1 (Sandeq) maupun kelas 2 dan 3 (Katinting) masih belum mencukupi. Hal ini diungkapkan oleh partisipan sebagai berikut.

"Ya, agak masih kurang. Masih kurang memang sebenarnya. Karena maksudnya itu mi, satu tim itu pegang kalau full bed, 18 orang." (P7)
"Kalau saya sih emm belum cukup. Masih kurang, masih kurang. Apalagi kalau pagi sih ramai, karena ada perawat primer, tapi kalau malam itu mereka cuma berdua untuk pasien 18..." (P8)

Mereka menuturkan bahwa jumlah tenaga perawat yang ada saat ini masih kurang, dan itu menjadi salah satu faktor penghambat bagi mereka dalam melakukan penatalaksanaan kepada pasien. Bahkan mereka sering mengalami kewalahan, sehingga tiap tim akan saling membantu untuk melakukan penanganan, meskipun pasien yang mereka tangani bukanlah pasien yang menjadi tanggung jawab dari tim mereka.

Selain itu, di RSP Unhas sendiri tidak ada tim tanggap darurat (rapid response), atau yang biasa disebut sebagai tim code blue. Hal tersebut diungkapkan oleh partisipan sebagai berikut.

"...Kalau emergensi ya langsung saja, nda ada tim yang tim code blue (sambil tertawa), nda ada. Nda ada di sini." (P7)

"kalau disini code bluenya kebetulan kami di rumah sakit belum ada tim code blue..." (P9)

Code blue merupakan sebuah kode yang digunakan untuk menandakan adanya kondisi gawat darurat (seperti henti jantung). Code blue juga sering digunakan di luar rumah sakit, yang biasanya juga berarti kondisi darurat seperti adanya ancaman bom, teroris, dsb (Stöppler, 2015). Tim code blue dapat diartikan sebagai sebuah tim yang dikhususkan untuk menangani kondisi gawat darurat yang terjadi di rumah sakit.

Di RSP Unhas menurut beberapa partisipan menyebutkan bahwa dahulu pernah dibentuk tim code blue. Bahkan dulu juga sudah ada beberapa orang yang ditunjuk untuk pembentukan tim code blue. Namun tim tersebut tidak sempat terbentuk dan juga tidak ber- 
jalan.

Faktor penghambat yang ketiga ialah tidak adanya SOP tentang keperawatan akut. Semua partisipan yang terlibat dalam penelitian ini menyebutkan bahwa di ruang rawat inap RSP Unhas tidak ada SOP tersendiri yang mengatur tentang keperawatan akut. Hal tersebut diungkapkan oleh partisipan sebagai berikut.

"Nda ada tertulis. Kecuali ada yang tidak tersosialisasi tapi kenyataan tdk ada sampai ke kami. Tidak ada, sesuai apa yang kami dapatkan saja di lapangan, sesuai dengan teori yang kami dapatkan selama ini" (P1)

"Nda ada, setahu saya nda ada..belum ada, saya nda tau kalau ada mi di rancang atau nda tau, saya belum tau, belum ada menyebar sampai saat ini" (P2)

SOP yang sudah ada ialah SOP berdasarkan tindakan. Jadi untuk pasien dengan kondisi akut akan diberi intervensi atau tindakan berdasarkan SOP yang sudah ada. Simamora (dalam Triwidyawati et al, 2013) menjelaskan bahwa SOP (Standar Operasional Prosedur) berarti tata cara atau tahapan yang dibakukan dan yang harus dilalui untuk menye-lesaikan suatu proses kerja tertentu.

\section{Harapan perawat untuk keperawatan akut}

Tema keempat tentang harapan perawat untuk keperawatan akut menghasilkan empat kategori, yaitu peningkatan kualitas perawat, penambahan jumlah tenaga perawat, pengadaan tim code blue dan pengadaan SOP keperawatan akut.

Beberapa partisipan menyebutkan bahwa mereka berharap kualitas dari perawat agar selalu ditingkatkan, baik dari segi ilmu maupun tindakan. Ada yang berharap agar perawat lebih meningkatkan kinerja serta kesadaran diri untuk mewujudkan motto dari RSP
Unhas sendiri, yaitu "tulus melayani". Ada pula yang berharap agar lebih sering lagi dilakukan seminar-seminar untuk meningkatkan dan meng-update ilmu pengetahuan dari perawat sendiri. Hal tersebut diungkapkan oleh partisipan sebagai berikut.

“...meningkatkan lah saja kinerja sehingga pasien-pasien merasa puas kaya' begitu, hmm..." (P4)

“...ee perawatnya harus diupdate terus ilmunya, jadi kita butuh juga ee seminar atau pun kuliahkuliah singkat toh, mengenai itu, penyakit itu,..." (P8)

Perawat merupakan tenaga kesehatan yang mempunyai waktu paling lama dalam berinteraksi dengan pasien dibandingkan tenaga kerja lain di rumah sakit. Profesi perawat dituntut untuk memberikan pelayanan kepe-rawatan yang bermutu, memiliki lan-dasan ilmu pengetahuan dan keteram-pilan yang kuat, disertai sikap dan tingkah laku yang profesional dan berpegang kepada etika keperawatan. Asuhan keperawatan yang berkualitas akan memberikan rasa aman dan nyaman kepada pasien serta memberikan pengaruh positif terhadap proses penyembuhan pasien. Untuk meningkatkan mutu asuhan keperawatan, hal-hal yang mempengaruhi antara lain : (1) Pimpinan yang peduli dan mendukung; (2) Ada kesadaran bahwa mutu harus ditingkatkan (standar mutu); (3) Tenaga keperawatan di-siapkan melalui upaya peningkatan pengetahuan, sikap dan ketrampilan dengan cara diadakan program diklat; (4) Sarana, perlengkapan dan lingkungan yang mendukung; (5) Tersedia dan diterapkannya Standar Asuhan Keperawatan (Pribadi, 2010).

Pribadi (2010) pernah melakukan penelitian tentang analisis pengaruh faktor pengetahuan, motivasi, dan persepsi perawat tentang supervisi kepala ruang terhadap pelaksanaan 
dokumentasi asuhan keperawatan di ruang rawat inap RSUD Kelet Provinsi Jawa Tengah di Jepara. Salah satu hasil penelitiannya mengungkap bahwa perawat yang memiliki pengetahuan tidak baik memiliki resiko untuk melaksanakan dokumentasi asuhan keperawatan tidak baik 6,280 kali lebih besar dibanding yang memiliki pengeta-huan baik. Hal tersebut telah menjelaskan akan pentingnya peningkatan kualitas dari perawat sendiri.

Selain peningkatan kualitas, harapan lain yang diungkapkan oleh beberapa partisipan ialah ditambahnya jumlah tenaga perawat. Penambahan ini dimaksudkan oleh partisipan agar jumlah tenaga perawat lebih memadai dan ideal, sehingga tidak akan terjadi lagi kewalahan dalam menangani pasien. Hal tersebut diungkapkan oleh partisipan sebagai berikut.

“...eee demi untuk apa itu namanya, memenuhi itu yang mottonya tulus melayani kan, ee ditambah lagi perawatnya toh, tenaganya di sini...." (P6)

"Ditambah, dan perawatnya dengan, maksudnya dengan kemampuan ilmu keperawatan yang lebih bagus, begitu." (P8)

Selain itu beberapa partisipan juga berharap agar dibentuknya tim tanggap cepat code blue di RSP Unhas, agar penanganan pasien gawat dan akut dapat lebih cepat dan lebih efisien. Hal tersebut diungkapkan oleh partisipan sebagai berikut.

"... kalau code blue mungkin bisa di anu juga kalau ada, bisa diadakan tapi kaya'nya belum memugkinkan, jumlah tenaga saja kita masih kekurangan...” (P1)

"kami berharapnya sih ada seperti itu (code blue) jadi kalau pasien yang fase-fase butuh mi tindakan anu toh emergency harusnya ada memang timnya kalau disini kita tidak, masih pake sistem MPKP modifikasi” (P5)

Seperti yang telah dijelaskan pada tema sebelumnya, tim code blue dapat diartikan sebagai sebuah tim yang dikhususkan untuk menangani kondisi gawat darurat yang terjadi di rumah sakit. Price, Applegarth, \& Price (2012) pernah melakukan penelitian yang berjudul Emergensi Code Blue: Analisa Tugas dalam Tim dan Memulai Pendidikan. Hasil penelitiannya menje-laskan bahwa pelatihan yang baik terhadap tenaga kesehatan yang terlibat dalam tim code blue dapat meningkatkan kualitas dari tim code blue tersebut, dan dapat meningkatkan kualitas pelayanan terhadap pasien di rumah sakit, khususnya pasien dengan kondisi gawat darurat.

Dan harapan terakhir dari beberapa partisipan ialah pengadaan SOP tentang keperawatan akut, agar penanganan pasien, khususnya pasien akut bisa lebih terstruktur dan lebih baik kedepannya. Hal ini diungkapkan oleh partisipan sebagai berikut.

"bagus juga kalau memang mau di buatkan standar toh, bilang berapa misalnya pelayanannya itu toh berapa lama, bagus ji juga, bisa, supaya lebih ini ki pelayanan keperawatannya toh" (P3)

"...kemudian kedua dibikinkan SOP, bagaimana perbedaan penatalaksanaan pasien akut dengan kronik,..." (P8)

Seperti yang telah dijelaskan di tema sebelumnya, SOP (Standar Operasional Prosedur) berarti tata cara atau tahapan yang dibakukan dan yang harus dilalui untuk menyelesaikan suatu proses kerja tertentu. Setiap sistem manajemen dengan kualitas yang baik selalu didasari oleh SOP yang kemudian disosialisasikan kepada seluruh pihak yang berkompeten untuk melaksanakannya. Keberadaan SOP dapat dijadikan sebagai acuan dalam 
melaksanakan tugas, sehingga dapat meningkatkan pelayanan dan menghindari tuntutan malpraktik (Natasia, Loekqijana, \& Kurniawati, 2014).

\section{KESIMPULAN}

Penelitian yang diakukan di ruang rawat inap kelas 1, 2 dan 3 RSP Unhas ini melibatkan sepuluh partisipan yang merupakan perawat yang bekerja di ruang rawat inap kelas 1,2 \& 3 RSP Unhas dengan pendidikan terakhir DIII Keperawatan dan S1 Ners serta telah bekerja minimal 1 tahun.

Dari hasil wawancara diketahui bahwa kejadian kondisi akut di ruang rawat inap RSP Unhas lebih sedikit daripada kondisi kronis. Untuk menangani kasus akut, perawat di ruang rawat inap RSP Unhas melakukan tindakan awal yaitu memantau TTV, lalu segera memberi tindakan emergency jika diperlukan, dengan tetap berkolaborasi dengan dokter.

Faktor pendukung bagi perawat di ruang rawat inap RSP Unhas dalam menangani pasien dengan kondisi akut ialah tersedianya trolly emergency, serta kerja sama antar perawat yang terjalin dengan baik. Sedangkan faktor penghambatnya ialah jumlah tenaga perawat yang masih kurang, tidak adanya tim code blue serta tidak ada SOP tersendiri yang mengatur tentang keperawatan akut.

Harapan perawat di ruang rawat inap kelas 1, 2 dan 3 RSP Unhas untuk keperawatan akut kedepannya ialah lebih meningkatkan lagi kualitas perawat, penambahan jumlah tenaga perawat, pengadaan tim code blue, serta pengadaan SOP keperawatan akut.

\section{DAFTAR PUSTAKA}

Anderson, N. (17 Maret 2011). List of acute diseases. Diakses tanggal 5 September 2016, dari website Livestrong.com - official partner of the livestrong foundation: http://www.livestrong.com/ article/135273-list-acute-diseases /

Anjaryani, W. D. (2009). Kepuasan pasien rawat inap terhadap pelayanan perawat di RSUD
Tugurejo Semarang (Tesis). Universitas Diponegoro, Semarang.

Bauk, I., Kadir, A. R., \& Saleh, A. (23 Juli 2013). Hubungan karakteristik pasien dengan kualitas pelayanan: persepsi pasien pelayanan rawat inap RSUD Majene Tahun 2013. Diakses tanggal 5 Januari 2017, dari website E-Journal Program Pascasarjana Unhas: http:// pasca.unhas.ac.id/jurnal/files/ dc1197b354ffd8ddac0952874bd9475c. pdf

Creswell, J. W. (2013). Qualitative inquiry \& research design third edition. USA: Sage Publications.

Mayasari, A. (2009). Analisis pengaruh persepsi faktor manajemen keperawatan terhadap tingkat kepuasan kerja perawat di ruang rawat inap RSUD Kota Semarang (Tesis). Universitas Diponegoro, Semarang.

Natasia, N., Loekqijana, A., \& Kurniawati, J. (2014). Faktor yang mempengaruhi kepatuhan pelaksanaan SOP asuhan keperawatan di ICU-ICCU RSUD Gambiran Kota Kediri. Jurnal Kedokteran Brawijaya, 28(1), 21-25.

Nazri, F., Juhariah, S., \& Arif, M. (2015). Implementasi komunikasi efektif perawat-dokter dengan telepon di ruang ICU Rumah Sakit Wava Husada. Jurnal Kedokteran Brawijaya, 28(2), 174-179.

Pribadi, A. (27 Desember 2010). Analisis pengaruh faktor pengetahuan, motivasi, dan persepsi perawat tentang supervisi kepala ruang terhadap pelaksanaan dokumentasi asuhan keperawatan di ruang rawat inap RSUD Kelet Provinsi Jawa Tengah di Jepara. Diakses tanggal 24 Januari 2017, dari website Diponegoro University Institutional Repository: http:/ / eprints.undip.ac.id/16228/

Price, J. W., Applegarth, O., \& Price, J. R. (2012). Code blue emergencies: a team task analysis and educational initiative. Canadian Medical Education Journal, 3(1), 4-20.

Rachmanta, R. (11 Desember 2015). Panduan troli emergensi. Diakses tanggal 24 Januari 2017, dari website DocSlide: http: / / documents.tips / documents / panduan-troli-emergensi.html

Rudyanto, E. (12 Juli 2013). Hubungan antara kecerdasan emosi dan kecerdasan spiritual dengan perilaku prososial pada perawat. Diambil kembali dari UPT Perpustakaan Universitas Sebelas Maret: https://eprints.uns.ac.id/2449/

Stöppler, M. C. (7 Juni 2015). What does code blue, code black, and code red mean? Diakses tanggal 5 Januari 2017, dari website MedicineNet.com: http://www. medicinenet.com/meaning_of_code_ black_and_code_blue/views.htm

Triwidyawati, D., Kristiyawati, S. P., \& Purnomo, S. C. (2013). Hubungan kepatuhan perawat 
dalam menjalankan SOP pemasangan infus dengan kejadian phlebitis. Diakses tanggal 5 Januari 2017, dari website STIKES Telogorejo Semarang E-Journal System: http://182.253.197.100/ejournal/index.php/ilmukeperawatan/ article/viewFile/114/140

WHO. (22 Juli 1946). WHO definition of health. Diakses tanggal 4 September 2016, dari website World Health Organization: http://www.who.int/about/definition/ en/print.html

WHO. (31 Januari 2013). Health systems and services: the role of acute care. Diakses tanggal 26 September 2016, dari website Bulletin of the World Health Organization: http://www.who.int/ bulletin/volumes/91/5/12-112664/en/

Yusuf, S. (2011). Profil diare di ruang rawat inap anak. Sari Pediatri, 13, 265-270. 